\title{
The Anodic Behaviour of Gold
}

\section{PART I - OXIDATION IN ACIDIC SOLUTIONS}

\author{
Michael J. Nicol \\ National Institute for Metallurgy, Randburg, South Africa
}

\begin{abstract}
The anodic behaviour of gold is of fundamental importance not only in processes involving the metal, such as its extraction, refining, electroplating, electroetching and electropolishing, but also in the many uses of gold in which its resistance to corrosion is critical. The first part of a review of this subject is presented here. Part II, dealing with reactions in alkaline media, will appear in the next issue of Gold Bulletin.
\end{abstract}

Gold is the most noble of metals. This property is, of course, the major factor contributing to its durability and to the fact that it normally occurs in nature as the native metal. Despite its generally high resistance to corrosion, gold can fortunately be made to corrode (or dissolve) freely in solutions containing appropriate complexing agents. This property of gold is put to use in the widely practised cyanide process for its recovery from ores, in its electrolytic refining in chloride solutions and in many applications in the metal finishing industry where it may be used as an anode in plating cells or is subject to electropolishing operations.

In view of the diverse conditions under which gold is forced by direct or indirect methods to operate as an anode, an understanding of its anodic behaviour in the presence of various complexing agents in aqueous solutions is often of importance. This review has been compiled with the object of providing the reader with a critical (albeit subjective) assessment of past and current views on the factors determining the behaviour of gold under oxidizing conditions, and of the mechanisms that have been proposed for the various reactions involved.

\section{Thermodynamic Aspects}

Although not always reliable as a gauge of chemical reactivity, thermodynamic data do provide a basis for the study of electrochemical reactions and can be of assistance in the interpretation of, and assignment of reactions to, observed electrochemical effects. For this reason, and because later discussion will be facilitated by their availability, a summary of the most relevant data on gold will first be given.

In the absence of ligands which stabilize one or other of the predominant oxidation states of gold in solution, namely $\mathrm{Au}(\mathrm{I})$ and $\mathrm{Au}(\mathrm{III})$, its chemistry is relatively simple and can be conveniently described using the thermodynamic diagram of potential against $\mathrm{pH}$ (Figure 1). The most important features of the diagram in relation to this review are as follows: (1) There is no significant region of stability for the uncomplexed $\mathrm{Au}^{+}$or $\mathrm{Au}^{3+}$ ions

(2) The most stable oxide of gold in the trivalent state, $\mathrm{Au}_{2} \mathrm{O}_{3}$, has a wide region of stability

(3) There is no stability region for $\mathrm{Au}(\mathrm{I})$ or $\mathrm{Au}(\mathrm{II})$ oxides. Aurous hydroxide, $\mathrm{AuOH}$, has supposedly been isolated ( 1 ), but evidence for its existence is sparse and no experimental thermodynamic data relating to it are available

(4) The formation of gold peroxide, $\mathrm{AuO}_{2}$, requires relatively high potentials, for instance that necessary at $\mathrm{pH} 1.0$ is $2.6 \mathrm{~V}$.

In the prescence of ligands that form complexes with $\mathrm{Au}(\mathrm{I})$ and/or $\mathrm{Au}(\mathrm{III})$, the potential against $\mathrm{pH}$ diagram is more complex than that shown in Figure 1 and reflects greater domains of stability of the soluble gold species. The chemistry of the various complexes of gold that can be formed with the common ligands in aqueous solutions has been described in a previous article (2) in this journal. T a e most significant aspect of this chemistry is the irfluence of the nature of the ligand on the stability of the ions and, thereby, on the standard reduction potentials of the corresponding couples. Data for the ligands that will be discussed in this review are recalled in Figure 2, in which the relative stabilities of the $\mathrm{Au}(\mathrm{III})$ and $\mathrm{Au}(\mathrm{I})$ complexes are compared. Thus, points below the diagonal line correspond to ligands (L) for which the $\mathrm{Au}(\mathrm{III})$ complexes $\mathrm{AuL}_{4}^{1-}$, are more stable than the corresponding $\mathrm{Au}(\mathrm{I})$ complexes $\mathrm{AuL} \mathrm{L}_{2}^{\mathrm{n}}$, the latter being the preferred species for those ligands appearing above the line. The information in Figure 2 has interesting consequences which will be discussed later.

Included in Figure 2 is a comparison of the potentials corresponding to the reduction of the various 
oxidized forms of the ligands $\left(\mathrm{X}_{2}\right)$ with those for the $\mathrm{Au}(\mathrm{I})$ complexes. On thermodynamic grounds, one would expect anodic oxidation of the ligand in preference to anodic dissolution of gold to occur only in those complexes positioned below the diagonal line. As will be seen, this prediction is generally borne out by experimental observations.

\section{Oxidation in Non-Complexing Media}

The electrochemical oxidation of noble metals and the reduction of oxide films on them have been

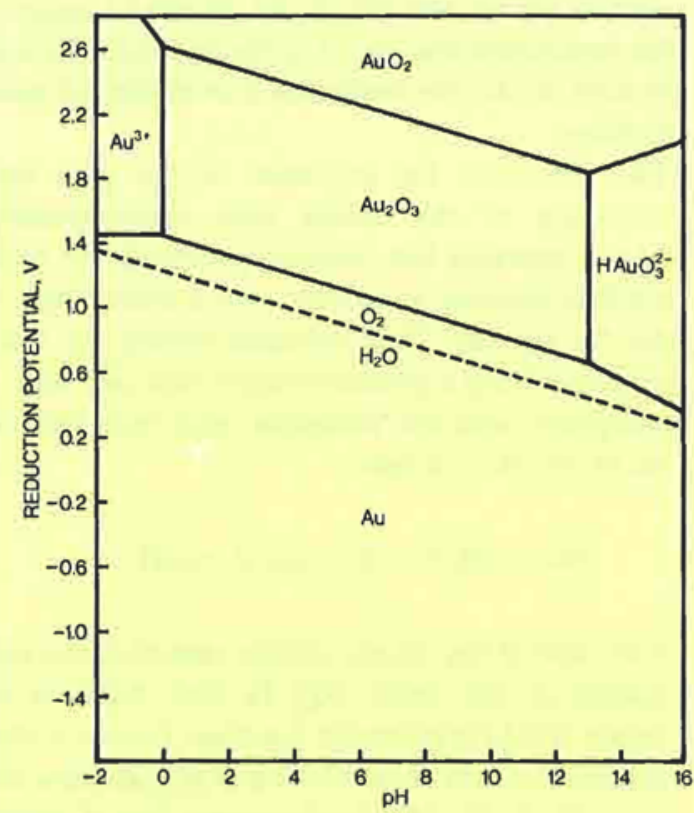

Fig 1. Potential against pH diagram for gold in aqueous solution at $25^{\circ} \mathrm{C}$. The concentration of al the soluble species is $10^{-4} \mathrm{M}$ actively investigated for many years. However, only recently have studies revealed the complexity of these processes on metals such as platinum and, to an even greater extent, gold. The formation of oxide films can have pronounced effects on the anodic dissolution of the metals and on the ease with which electrons can be transferred to reactants in solution. The factors governing the formation and properties of these films are therefore important for an understanding of the anodic behaviour of the metals. This topic has been the subject of several reviews $(4,5,6)$, but these were not written with the anodic dissolution behaviour of gold specifically in mind.

\section{Early work}

Much of the early work (7 to 16 ) on the electrochemical oxidation of gold was carried out with galvanostatic methods that lack the sensitivity and resolution required for detailed studies. However, this work provided an overall picture of the oxidation of gold which has undergone considerable refinement in recent years. The major findings of the pre-1972 researches were as follows:

(1) Thick oxide layers can be grown on gold, but not on platinum electrodes by anodization at high potentials. Evidence for this is provided by the results of Laitinen and Chao (9) shown in Figure 3. The amount of oxide (expressed in terms of millicoulombs/square centimetre) produced by anodization for 3 minutes in $1 \mathrm{M}$ perchloric acid at various potentials was determined by cathodic stripping at constant current. After anodization at low potentials, the stripping charge corresponds approximately to that required for
Standard reduction potentials of complexes of $A u(I)$ and $A u(I I I)$ with:

cyanide
thiosulphate
iodide
thiocyanate
sulphite
bromide
chloride ions
nd with thiourea and water.

These are compared with those for the oxidation of the corresponding ligands to the dimeric species. After $(2,3,4)$

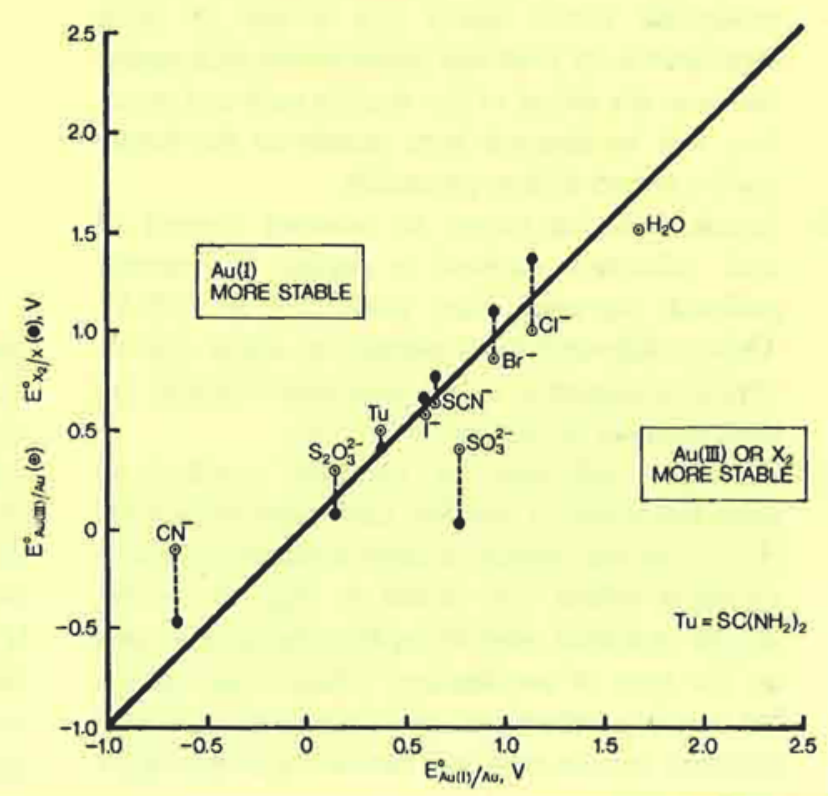




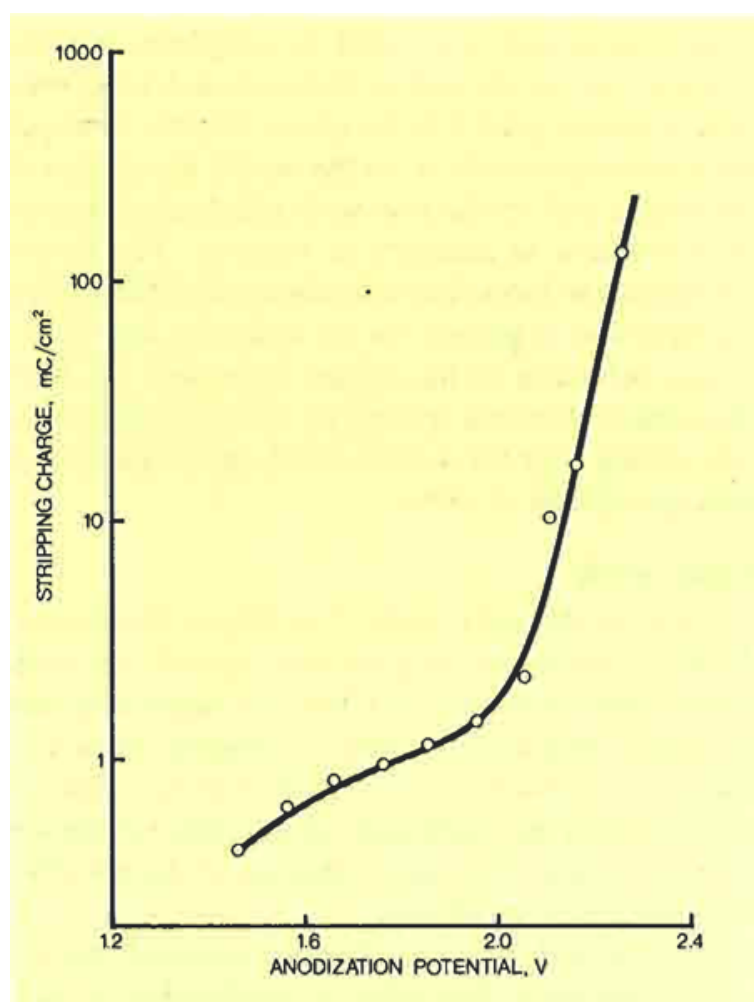

Fig. 3 Variation of the amount of oxide formed lexpressed in terms of the electrical charge required for subsequent stripping) by the anodization of a gold electrode at various potentials for 3 minutes in I $M$ perchloric acid. After (9)

one-electron oxidation of the surface atoms of the gold (close to $0.4 \mathrm{mC} / \mathrm{cm}^{2}$ ). At potentials above $2 \mathrm{~V}$, oxidation is rapid and the surface becomes coated with a dark orange film that has been shown (8) to consist of hydrated $\mathrm{Au}_{2} \mathrm{O}_{3}$. Because potentials above about $1.8 \mathrm{~V}$ are of little significance for practical applications, this region has been the object of few studies only and attention will be devoted here mostly to the better known region of low potentials

(2) Anodic-charging curves at constant current in acid solutions showed a region of smooth potential increases from about 1.3 to $1.75 \mathrm{~V}$. This is followed by a plateau at about $1.8 \mathrm{~V}$, which corresponds to the potential required for the evolution of oxygen $(9,10,14)$

(3) Cathodic reduction (at constant current) of anodized surfaces yielded chronopotentiograms $(9,10,14)$ that appear to show a single arrest at a potential which was found to depend on the anodic potential used to oxidize the surface and on the time of anodization. These observations led early workers to conclude that a single oxidized species only was formed by anodization of the gold
(4) At all potentials, an initial rapid oxidation is followed by slow growth of the oxide film $(10$, $12,13)$. Oxides formed over longer anodization times are more difficult to reduce than those formed over short times. This 'ageing' effect is greatest at the lower potentials, despite the greater thickness of the oxides formed at the high potentials

(5) The rest potential of a gold electrode anodized to various potentials in $l M$ perchloric (9) or sulphuric acid (16) was found to be relatively constant at $1.30 \mathrm{~V}$, which is sufficiently close to those $(1.31$ to $1.51 \mathrm{~V})$ reported by various authors (4) for the $\mathrm{Au}_{2} \mathrm{O}_{3} / \mathrm{Au}$ couple to support the conclusion that $\mathrm{Au}_{2} \mathrm{O}_{3}$ is the product which is formed in the electrochemical oxidation of gold surfaces

(6) The potentials for oxidation of the gold and reduction of the oxides shift approximately $60 \mathrm{mV}$ towards less positive potentials for each ten-fold decrease in acidity over a wide range in $\mathrm{pH}(9,10,14)$. This indicates control by reactions involving a proton/electron ratio of 1 and is consistent with the formation and reduction of $\mathrm{Au}_{2} \mathrm{O}_{3}$ by the reaction:

$$
2 \mathrm{Au}+3 \mathrm{H}_{2} \mathrm{O}+6 \mathrm{e} \rightleftharpoons \mathrm{Au}_{2} \mathrm{O}_{3}+6 \mathrm{H}^{+}
$$

(7) The ratio of the anodic charge passed in the formation of the oxide $\left(Q_{a}\right)$ to that required to reduce it $\left(Q_{c}\right)$ is generally less than 1 , even at low potentials where the evolution of oxygen does not occur $(8,9,10,14)$. Furthermore, loss of oxide, as measured by $Q_{c}$, is observed when an anodized electrode is allowed to remain in acid solutions under open circuit conditions. Reactions which have been put forward to explain these observations have included oxidation of water by $\mathrm{Au}_{2} \mathrm{O}_{3}$ (9) (Such oxidation is possible from a thermodynamic point of view, since the $\mathrm{H}_{2} \mathrm{O} / \mathrm{O}_{2}$ line in Figure 1 lies below that for the $\mathrm{Au} / \mathrm{Au}_{2} \mathrm{O}_{3}$ couple) and chemical dissolution of the oxide to form $\mathrm{Au}^{3+}$ ions $(8,10)$.

Based on these early observations, a fairly general consensus of opinion was reached on the gross features of the reactions taking place during the anodic oxidation of gold in solutions of noncomplexing acids. Thus, it was accepted that chemisorption of oxygen begins at potentials above about $1.4 \mathrm{~V}$, monolayer coverage is approached at about $2 \mathrm{~V}$ and, at higher potentials, the growth of a layer of bulk oxide that appears to correspond to $\mathrm{Au}_{2} \mathrm{O}_{3}$ in acid solutions and to $\mathrm{Au}(\mathrm{OH})_{3}$ in alkaline solutions follows. The nature of the chemisorbed oxygen layer was however not known with any certainty. 
Fig. 4 Effect of anodic potential sweep rate on the proportions of different intermediate species detected by reduction at a constant cathodic sweep rate of a gold electrode in $1 \mathrm{M}$ perehloric acid. After (17)

\section{Recent Advances}

In the 1970's, much of the experimental work on the oxidation and reduction at gold surfaces underwent considerable refinement as a result of the use of advanced techniques such as cyclic voltammetry. These methods are eminently suited to the resolution of 'fine structure' in current-potential relationships and to the study of anodic film growth and recrystallization kinetics. The use of modern optical and spectroscopic techniques, such as ellipsometry and X-ray photoelectron spectroscopy, has also contributed to current knowledge of the nature of the oxide films.

One of the most significant conclusions drawn from recent work is that the process of anodic oxidation of gold is not as simple as previously supposed. For instance, cyclic voltammograms (17) for a gold electrode in acid solution (see Figure 4) indicate that the oxidation and reduction processes involve several reactions, as evidenced by the multiplicity of the peaks. Much effort has been devoted to the identification of the origins of these peaks.

If single crystal gold electrodes with exposed planes of defined symmetry are used (18), only single peaks are observed for oxide formation and, at low potential sweep rates and anodic limits, for oxide reduction. Three voltammograms obtained in this manner by Dickertmann et al. (18) are shown in Figure 5 for polycrystalline and single crystal electrodes with the (100) and (111) faces exposed. Repeated cycling of the electrodes to potentials below $1.9 \mathrm{~V}$ produced no noticeable change in the shape of the curves. However, anodization at potentials above $2 \mathrm{~V}$ resulted in roughening of the surface of single crystal electrodes with apparent film recrystallization to yield voltammograms of the polycrystalline type. Also evident for high anodic potential limits, was an additional reduction peak that had previously been observed by Rand and Woods (19) when the anodic limit was extended into the region where the chargepotential relationship (Figure 3) revealed a change in the anodization characteristics.

More recent work $(17,20)$ has added considerably to the knowledge of ageing and recrystallization processes in oxide films on gold. Using fast-scan voltammetry, it is possible to distinguish several cathodic peaks for the reduction of oxide films produced even at low anodic potentials. Figure 4 shows some typical curves obtained in perchloric acid solutions at various anodic, but constant cathodic,

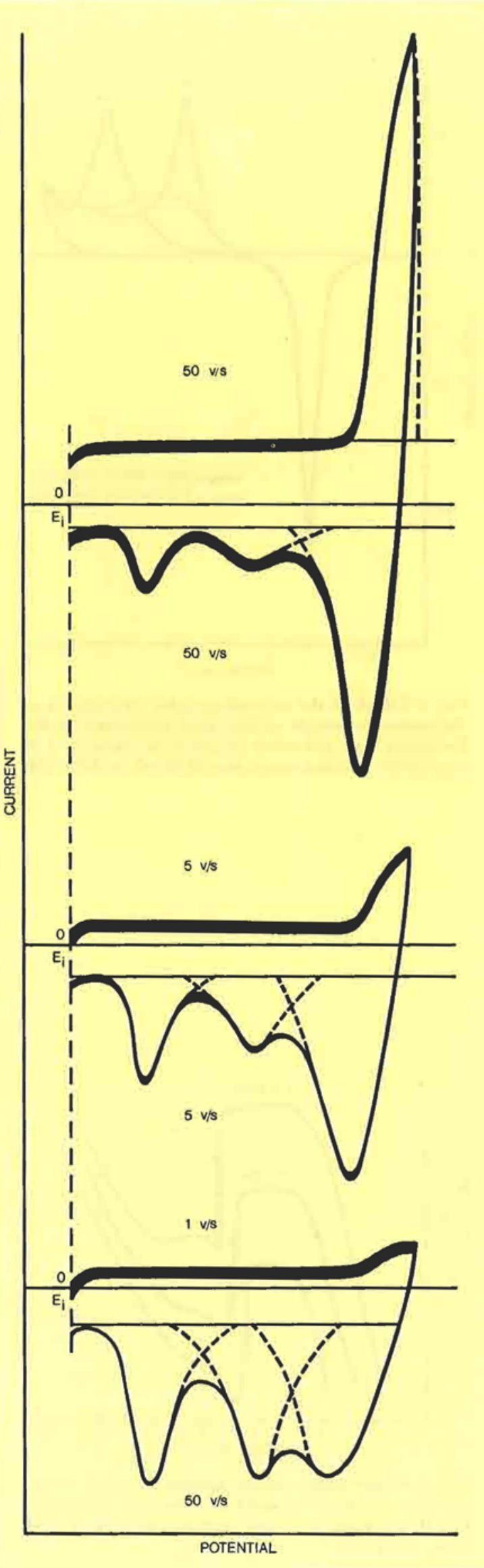




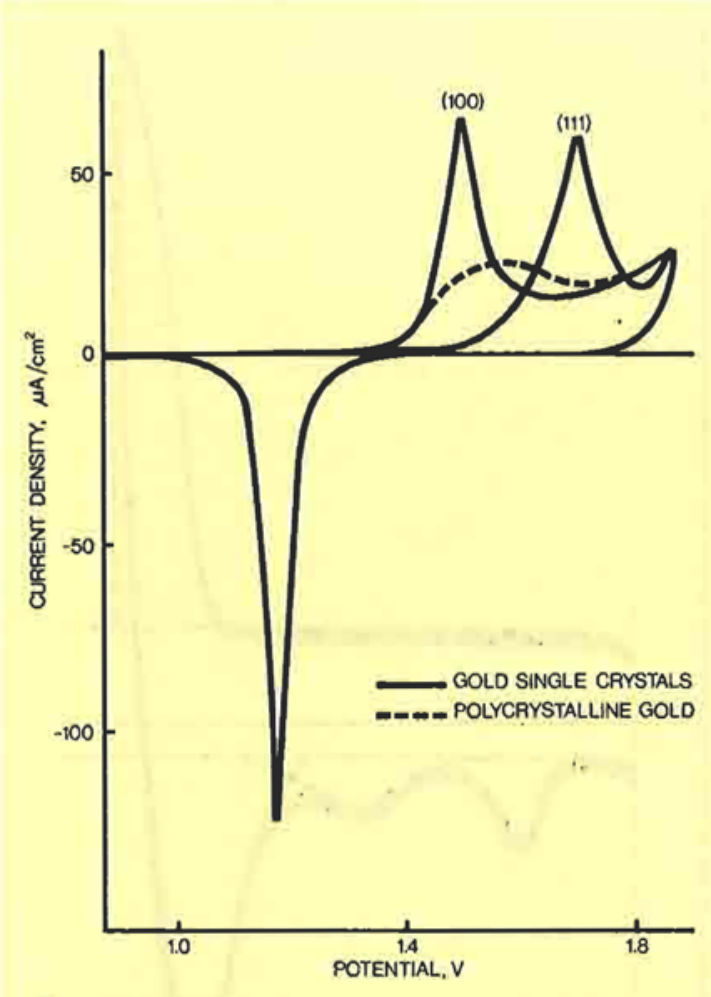

Fig. 5 Effect of the crystallographic orientation of the surface of single crystal gold electrodes on the formation and reduction of oxide on them in $1 \mathrm{M}$ perchloric acid at a sweep rate of $10 \mathrm{mV} / \mathrm{s}$. After (18)

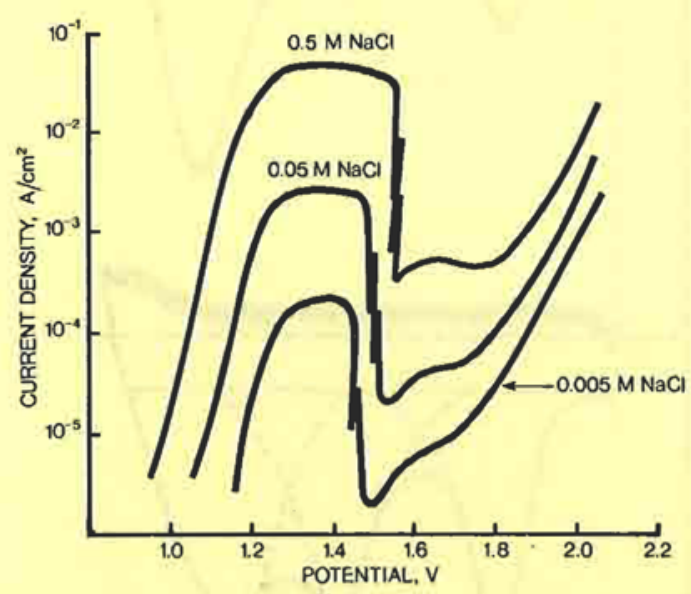

Fig. 6 Steady-state current against potential curves for the oxidation of gold in solutions containing $0.5 \mathrm{M}$ sulphuric acid and various amounts of chloride. After (28) sweep rates. Although the charge involved is less than that required for monolayer coverage, the results indicate relatively rapid transformations of the initial anodic product. Thus, the faster the anodic sweep, the greater the amount of the more reactive (as measured by the area under the least cathodic reduction peak) anodic product retained during the potential scan. The behaviour of gold in sulphuric acid is somewhat different, the oxidation starting at slightly lower anodic potentials. Here, five reduction peaks have been observed but, as pointed out by Arvia's group (17) and others (18, 19), caution should be exercised in the assignment of all these peaks to surface oxides, because trace impurities could be at least partially responsible for them. The mechanism proposed by Arvia's group (17) to explain these effects involves the initial formation of an adsorbed $\mathrm{AuOH}$ species that is susceptible either to further oxidation to a higher 'oxide' or to chemical disproportionation to a more stable surface oxide with a stoichiometry comparable to that of $\mathrm{Au}_{2} \mathrm{O}_{3}$. These species are envisaged as giving rise to different reduction peaks, the relative magnitudes of which vary with the limit of anodic potential and the time allowed for the chemical disproportionation reaction to take place. However, this interpretation is open to debate, since it ignores the polycrystalline nature of the surfaces employed in the experiments. Indeed, as pointed out by Dickertmann et al. (18), the formation of epitaxial surface oxides is possible (and even likely) and could give rise to multiple reduction peaks on a polycrystalline surface. Rapid transition of an epitaxial oxide to an oxide independent of the substrate could explain the ageing effects that are observed. Work similar to that of Arvia's group (17), but using single crystal electrodes, might solve these problems of interpretation.

Studies (18) of the formation kinetics of oxide layers on gold as a function of their thickness have resulted in general agreement that formation of the first layer is relatively reversible (fast) and that its rate of formation depends on the crystallographic orientation of the gold surface. For thicker layers $(0.2$ to $0.3 \mathrm{~nm})$, however, the rate of growth is independent of the substrate orientation and is governed largely by the migration of ions through the oxide.

Several investigations $(8,9,10,21,22)$ have shown that dissolution of gold occurs during anodization and during the reduction of oxide films in acidic sulphate or perchlorate solutions. In an elegant study, Cadle and Bruckenstein (21), using ring-disc electrodes, determined the rate of dissolution by collecting the dissolved gold on a platinum ring electrode. Dissolution was observed at potentials greater than $1.38 \mathrm{~V}$ where $\mathrm{Au}$ (III) was found to be the predominant soluble species. At potentials above $1.7 \mathrm{~V}, \mathrm{Au}(\mathrm{I})$ was also 
detected in significant amounts. Gold dissolution, primarily as $\mathrm{Au}(\mathrm{III})$, was also observed during the reduction of oxide films. Mechanisms were not proposed beyond the unlikely suggestion that an oxide $\mathrm{AuO}_{\mathrm{x}}$ is reduced to a soluble $\mathrm{Au}(\mathrm{III})$ species that can be further reduced to metal or can diffuse into the solution. The accurate measurement of the very low dissolution rates involved is the major obstacle to more detailed understanding of the factors influencing the dissolution of gold in non-complexing solutions. However, as pointed out by Duncan and Frankenthal (22), such dissolution and re-deposition of gold can have important practical consequences in the thin film and integrated circuit technologies.

Ellipsometric (23) and optical reflectance techniques (24) have been applied to in situ observation of the formation of oxide films on gold electrodes. Although both have enabled detection of changes in the optical properties of gold surfaces in the potential regions of interest, the many assumptions required for interpretation of the experimental data have resulted in little new information being gathered on the chemical nature of the anodic products. X-ray photoelectron spectroscopy can, in theory, provide useful information on the chemistry of surfaces, but it suffers from the disadvantage that it cannot by used in situ. Nevertheless, gold $4 f$ and oxygen 1 s spectra (25) of a gold surface anodized in dilute sulphuric acid are similar to those of chemically prepared $\mathrm{Au}_{2} \mathrm{O}_{3}$.

\section{Oxidation in Halide Solutions}

Anodic oxidation of a gold electrode in acidic solutions containing chloride (or bromide) ions results in a marked increase in the rate of dissolution of the metal by virtue of the increased stability of $\mathrm{Au}(\mathrm{I})$ and $\mathrm{Au}(\mathrm{III})$ chloro-complexes (Figure 2). This forms the basis for the Wohlwill process for the electrolytic refining of gold, the overall chemistry of which was recently reviewed in this journal (26). Several studies have been made of the fundamental electrochemistry associated with the dissolution of gold from chloride solutions (26 to 33 ). While most authors agree on the conditions under which the passivation of gold anodes occurs and on the mechanism by which this passivation is induced, the results for active dissolution and the interpretations offered are not altogether consistent. This is particularly true with regard to the participation in the reactions of gold species of lower valencies. This aspect will now be reviewed in some detail, before discussing the passivation behaviour of gold in acidic chloride solutions.

\section{Dissolution in Chloride Solutions}

Heumann and Panesar (28), in a study of the anodic dissolution of gold in acidified sodium chloride solutions, found that both $\mathrm{Au}(\mathrm{I})$ and $\mathrm{Au}(\mathrm{III})$ were the pro- ducts of dissolution. They were able to distinguish analytically between the two species and obtained current-potential data that yielded Tafel plots for potentials below about $1.2 \mathrm{~V}$ (Figure 6) for production of $\mathrm{Au}(\mathrm{I})$ and $\mathrm{Au}(\mathrm{III})$ under various conditions. Their results showed that the formation of $\mathrm{Au}(\mathrm{I})$ predominates at low current densities only and that increased chloride concentration (at constant current) enhances production of $\mathrm{Au}(\mathrm{I})$. Reaction orders of approximately 2 were obtained for the dependence of the rates of dissolution on the concentration of chloride ions for the formation of both $A u(I)$ and $\mathrm{Au}(\mathrm{III})$. Corresponding reaction orders of 0.92 and 0.67 were also derived for the dependence on the proton concentration. At higher potentials in the range 1.2 to $1.4 \mathrm{~V}$, the current was found to be controlled by the diffusion of chloride ions to the surface of the gold electrode. At a potential of about $1.5 \mathrm{~V}$, passivation was observed, which was attributed to the formation of an oxide layer. Heumann and Panesar (28) did not attempt the derivation of a detailed reaction mechanism from their data.

Gaur and Schmid (29), in a study aimed primarily at clarifying the mechanism involved in the passivation of gold in dilute chloride solutions, obtained steady-state curves of current against potential for the pre-passive region and assumed that $A u(I I I)$ was the product of dissolution. No mechanism was proposed. In a study of the deposition of gold from chloride solutions, Harrison and Thompson (30) found that the reduction of $\mathrm{Au}(\mathrm{III})$ could be characterized by a Tafel slope of $60 \mathrm{mV}$ and suggested a fast oneelectron first step followed by a slow chemical step. The observed Tafel slope of $84 \mathrm{mV}$ for the anodic reaction was interpreted in terms of a slow step involving transfer of the first electron. Despite this, the production of $\mathrm{Au}(\mathrm{I})$ was not considered, although the authors recognized that results of impedance measurements pointed to the possibility of a somewhat more complicated process.

An extensive study of gold dissolution in chloridecontaining acidic media was recently published by Arvia's group (31). The cathodic sweeps of cyclic voltammograms indicated the production of $\mathrm{Au}(\mathrm{I})$ by the anodic reaction, but the authors made no attempt to measure the relative yields of $\mathrm{Au}(\mathrm{I})$ and $\mathrm{Au}(\mathrm{III})$ or to analyze the data in terms of these yields. They found a first-order dependence of the rate of active dissolution on the chloride concentration. The mechanism proposed for the anodic reaction involves the highly unlikely heterogeneous disproportionation of adsorbed $\mathrm{Au}(\mathrm{I})$ and does not allow for the direct anodic oxidation of $\mathrm{Au}(\mathrm{I})$ to $\mathrm{Au}(\mathrm{III})$. Furthermore, this mechanism predicts that $\mathrm{Au}(\mathrm{I})$ should be the major dissolution product at low concentrations of chloride, in contradiction with the experimental 


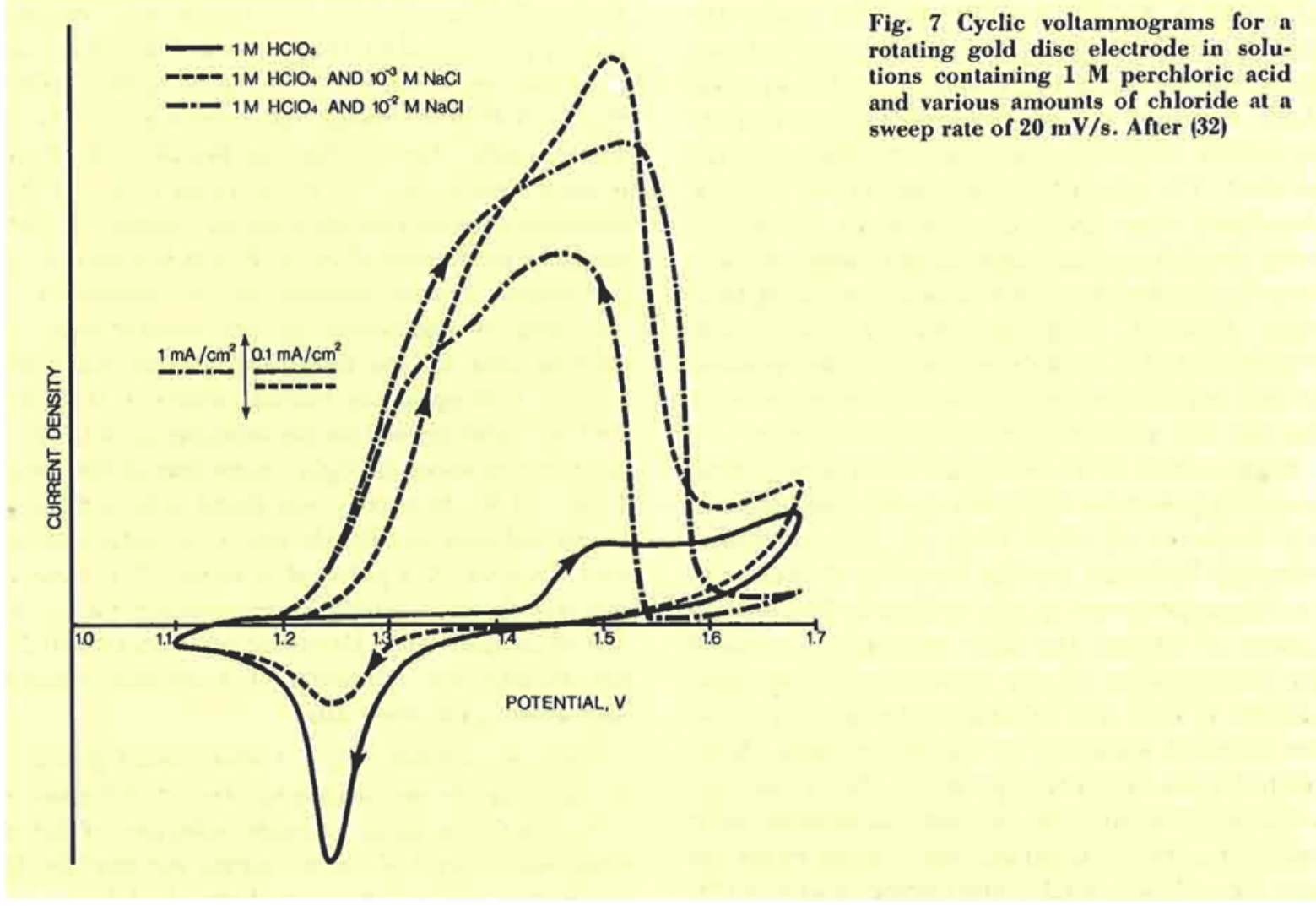

observations of Heumann and Panesar (28) and Schalch and Nicol (26).

The latter workers (26) have made a detailed study of the dissolution and passivation of gold in chloride solutions as part of a general fundamental investigation into its electrolytic refining. The relative amounts of $\mathrm{Au}(\mathrm{I})$ and $\mathrm{Au}(\mathrm{III})$ formed by anodic dissolution under various conditions were obtained from the charge required to strip a known amount of gold deposited onto a rotating platinum disc electrode. It was found that the fraction of gold that reported as $A u(I I I)$ increased with the potential, but decreased with increased chloride concentration and decreased rotation speed at all potentials in the active region. These results are consistent with a mechanism involving the formation of $\mathrm{Au}(\mathrm{I})$ as an intermediate species that can either be further oxidized to Au(III) in a rate-determining two-electron step or diffuse into the solution. The rate of dissolution as $\mathrm{Au}(\mathrm{I})$ was found to be proportional to the chloride concentration, as was the oxidation of $\mathrm{Au}(\mathrm{I})$ to $\mathrm{Au}(\mathrm{III})$. Further evidence supporting this mechanism was obtained from a study of the oxidation of $\mathrm{Au}(\mathrm{I})$ at a platinum electrode. The kinetic parameters for this latter reaction were similar to those derived from an analysis of the anodic dissolution of gold. A preliminary study showed that the rate of disproportionation of $\mathrm{Au}(\mathrm{I})$ in chloride solutions is extremely slow (its half-life is of the order of hours) and this cannot reasonably be accommodated in the mechanism proposed by Arvia's group (31.)

\section{Passivation in Chloride Solutions}

As shown in Figure 6, passivation of gold in chloride-containing acidic media occurs at potentials above about $1.4 \mathrm{~V}$ and is accompanied by a noticeable instability or oscillation of the current in the vicinity of the passivation potential. Cyclic voltammograms, obtained (32) using a rotating gold disc in perchloric acid solutions with and without added chloride, are shown for comparative purposes in Figure 7. As discussed previously, the plateau observed in the curve at potentials above about $1.45 \mathrm{~V}$ in the presence of chloride is due to the formation of an oxide layer on the surface of the gold. Thus, with added chloride $\left(10^{-3} \mathrm{~mol} / \mathrm{litre}\right)$, a curve results that indicates passivation, but it is noticeable that no re-activation of the electrode takes place during the reverse sweep and the cathodic peak due to reduction of the oxide is evident. In the solution with a chloride concentration of $10^{-2} \mathrm{~mol} / \mathrm{litre}$, passivation is at somewhat higher potentials, re-activation occurs during the reverse sweep and there is no cathodic peak, indicating that no oxide is present. These experiments confirm the theory proposed by several authors $(27,28,29,31)$ that the formation of an oxide film on gold results in 
passivation. It is also obvious that chemical dissolution of the oxide film is possible in chloride solutions. It is this anodic formation of an oxide film and its chemical dissolution that cause the oscillation in the current near the passivation potential. This phenomenon has been discussed in some detail in a recent article by Arvia's group (33).

Several authors $(29,31,33)$ have attempted to devise quantitative models to account for the shape of the curves in Figure 5. These have been based on simple and complex representations of the variation with potential of gold electrode coverage by oxide. Although some success has been achieved, it is unlikely that a general model will be established unless account is taken of the relative amounts of $\mathrm{Au}(\mathrm{I})$ and $\mathrm{Au}(\mathrm{III})$ produced, of the chemical dissolution of the oxide in chloride solutions and of the adsorption of chloride ions on the surface of gold. This latter aspect was discussed at length by Cadle and Bruckenstein (34) who used ingeniously the ring-disc electrode technique to confirm the adsorption of chloride on gold at various potentials.

\section{Bromide and Iodide Solutions}

While it can be reasonably argued that the anodic behaviour of gold in acidic chloride solutions is, despite areas of minor controversy, fairly well understood, the same cannot be said for the electrochemistry of gold in the presence of the other complexing halides (bromide and iodide). The use of bromide solutions has been advocated (35) for the anodic stripping analysis of gold, but the kinetics and mechanisms of the anodic process have apparently not been studied in any detail beyond that reported by Gaur and Schmid (29). These authors inferred from a cyclic voltammetric experiment that gold pro-

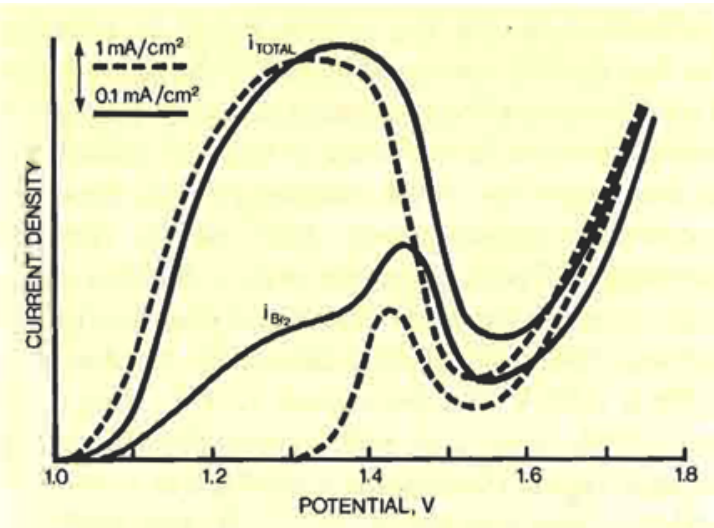

Fig. 8 Current against potential curves for the oxidation ( $\left.i_{\text {TOTAL }}\right)$ of a rotating gold disc electrode in solutions containing $0.1 \mathrm{M}$ sulphuric acid and 0.001 or $0.01 \mathrm{M}$ bromide. Also shown are the corresponding partial currents for the production of bromine $\left(\mathrm{i}_{\mathrm{Br}_{2}}\right)$, as measured at a platinum ring electrode bably dissolves and passivates in a dilute bromide solution much as it does in chloride solutions, with the difference that bromine evolution $\left(\mathrm{E}^{\circ}=1.08 \mathrm{~V}\right)$ is possible at potentials close to those required for the oxidation of gold to $\mathrm{AuBr}_{2}^{-}\left(\mathrm{E}^{\circ}=0.960 \mathrm{~V}\right)$ or $\mathrm{AuBr}_{4}$ $\left(\mathrm{E}^{\circ}=0.854 \mathrm{~V}\right)$. No study of the gold-iodide system has been reported, but its characteristics are expected to be similar to those of the gold-bromide system, with the additional possibility of passivation by insoluble AuI.

Preliminary experiments carried out in the writer's laboratory with a gold disc-platinum ring electrode have shown that, depending on the potential and the concentration of bromide ions, various proportions of $A u(I), A u(I I I)$ and bromine are produced at the anode. Figure 8 gives the results of some experiments where the ring was held at a potential $(0.85 \mathrm{~V})$ at which bromine can be detected by reduction to bromide, but at which $\mathrm{Au}(\mathrm{I})$ and $\mathrm{Au}(\mathrm{III})$ are electrochemically inactive. The most important conclusions to be drawn from these curves are that:

(1) The shape of the curve for the anodic dissolution of gold is similar in most respects to that obtained in chloride solutions

(2) Passivation of the gold occurs at roughly the same potential as that observed in chloride solutions and may therefore also be attributed to the formation of an oxide film

(3) At low potentials, the oxidation of bromide ions consumes only a small fraction of the total current. At potentials approaching the passivation region, bromine is the major anodic product

(4) The proportion of the total current consumed in the production of bromine decreases with increasing bromide concentration.

It is apparent that further work is required to establish the mechanisms and details of the reactions involved, even though these do seem to parallel those in chloride solutions rather closely.

\section{Oxidation in Thiourea Solutions}

$\mathrm{Au}(\mathrm{I})$ forms the strong cationic complex $\mathrm{Au}\left[\mathrm{SC}\left(\mathrm{NH}_{2}\right)_{2}\right]_{2}^{+}$with thiourea and this has been the basis for a number of schemes proposed for the recovery of gold from ores and concentrates (36). However, despite the potential applications of thiourea in the extractive metallurgy of gold, the relevant electrochemistry has not received much attention. In fact, the only publication of any significance in this area is that of Groenewald (37), who investigated the anodic characteristics of gold in acidic solutions of thiourea complex. He used steady-state measurements of the current at varius potentials and coulometric measurements of the amount of gold dissolved from a rotating gold disc, and found that gold dissolves as $\mathrm{Au}(\mathrm{I})$ with 100 per cent current efficiency at overpotentials below about $0.3 \mathrm{~V}$ (Figure 9). 
Comparison of the limiting current with that calculated for the reaction:

$$
\mathrm{Au}+2 \mathrm{SC}\left(\mathrm{NH}_{2}\right)_{2} \rightarrow \mathrm{Au}\left[\mathrm{SC}\left(\mathrm{NH}_{2}\right)_{2}\right]_{2}^{+}+\mathrm{e}
$$

showed that dissolution of gold is largely diffusioncontrolled in the plateau region. Analysis of the data at low overpotentials yielded kinetic parameters

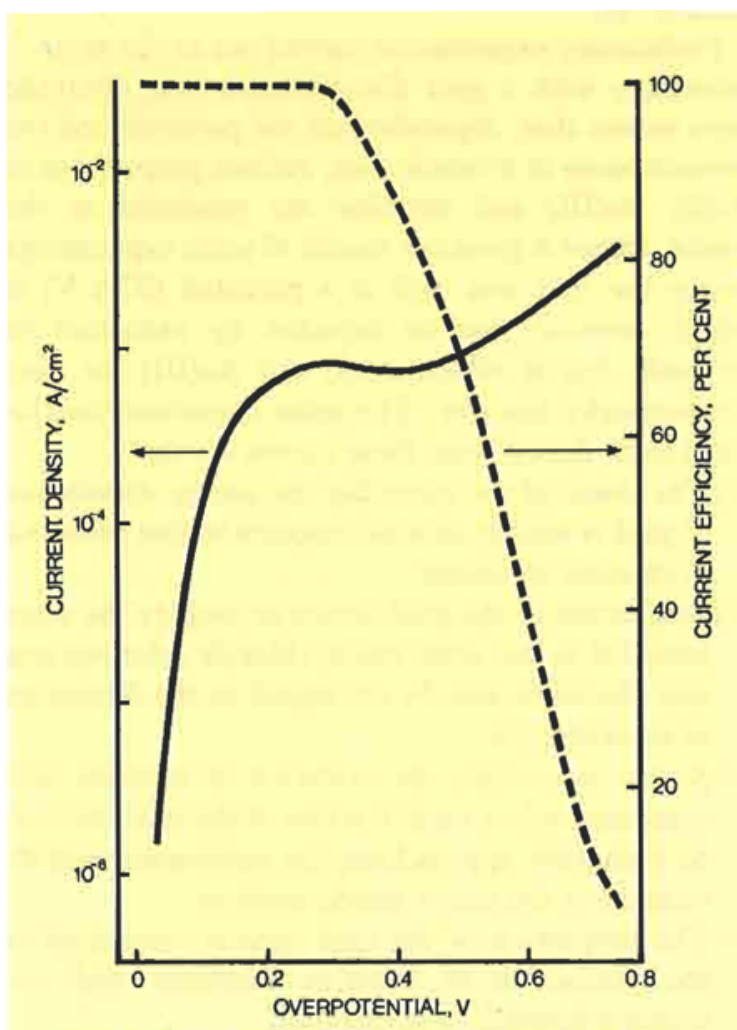

Fig. 9 Effect of overpotential on the anodic dissolution of gold and the current efficiency of its dissolution into a solution containing $0.1 \mathrm{M}$ sulphuric acid and $0.1 \mathrm{M}$ thiourea at $30^{\circ} \mathrm{C}$. After (37)

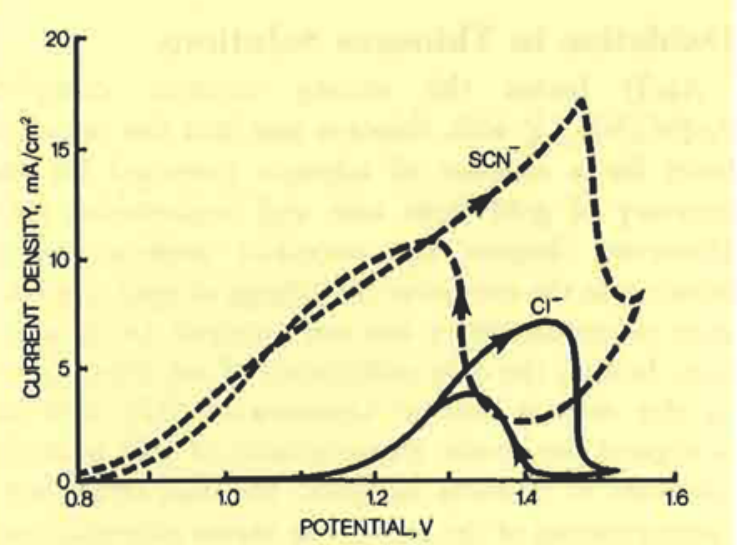

Fig. 10 Cyclic voltammograms for the oxidation of a rotating gold disc electrode in solutions containing $0.1 \mathrm{M}$ sulphuric acid and either $0.01 \mathrm{M}$ chloride or $0.01 \mathrm{M}$ thiocyanate which showed that the reaction given above is relatively reversible. The decrease in current efficiency at high overpotentials was attributed to the loss of thiourea by oxidation to formamidine disulphide and/or other products, with a simultaneous decrease in the rate of gold dissolution.

\section{Oxidation in Thiocyanate Solutions}

The thiocyanate ion, $\mathrm{SCN}^{-}$, is isoelectronic with the halide ions and displays pseudo-halide properties in many of its reactions. It may therefore be expected to exert an influence on the anodic behaviour of gold similar to that of chloride or bromide ions. To some extent this is apparently true. For example, the complexes $\mathrm{Au}(\mathrm{SCN})_{2}^{-}$and $\mathrm{Au}(\mathrm{SCN})_{4}^{-}$are well known, and thiocyanogen, $(\mathrm{SCN})_{2}$, can be produced by oxidation of thiocyanate ions.

The only publication on the anodic reactions of gold with thiocyanate ions is that of Arvia's group (38) who investigated these reactions in acetonitrile medium. It was found that, at potentials below $0.35 \mathrm{~V}$, gold dissolved predominantly as the $\mathrm{Au}(\mathrm{I})$ complex, while the presence of $\mathrm{Au}$ (III) in anodic solutions produced at higher potentials was inferred from the ultraviolet absorption spectra of the latter. Oxidation of thiocyanate and/or the solvent occurred at potentials above $0.55 \mathrm{~V}$. A mechanism involving the formation of $\mathrm{Au}(\mathrm{SCN})_{2}^{-}$by oxidation of an adsorbed AuSCN species and the formation of $\mathrm{Au}(\mathrm{SCN})_{4}^{-}$by disproportionation of the $\mathrm{Au}(\mathrm{I})$ species was proposed, similar to that previously suggested by the same group (31) for the anodic dissolution of gold in chloride solutions.

Cyclic voltammograms obtained in the writer's laboratory for a rotating gold disc electrode in sulphuric acid solutions containing respectively chloride and thiocyanate ions are shown for comparative purposes in Figure 10. The similarity of the curves in respect of shape, passivation potential and re-activation during the reverse sweep is apparent. The fact that the current is higher in the active region in the presence of thiocyanate ions than in presence of chloride ions can be explained in terms of oxidation of the thiocyanate by a multi-electron process. However, coulometric measurements have shown that the dissolution of gold consumes only a fraction of the total current in the active region and that this fraction decreases from 20 per cent (assuming dissolution as $\mathrm{Au}(\mathrm{I}))$ at $0.95 \mathrm{~V}$ to 4 per cent at $1.15 \mathrm{~V}$. This is not unexpected, since it is well known (39) that in this potential region thiocyanate is oxidized at a platinum surface to thiocyanogen $\left(E^{\circ}=0.77 \mathrm{~V}\right)$ and, finally, to sulphate and cyanide ions.

\section{Summary}

Table I summarizes the salient features of the anodic behaviour of gold in acidic solutions in the 
Table I

Summary of the Anodic Behaviour of Gold in Acidic Solutions

\begin{tabular}{|c|c|c|c|c|c|}
\hline Ligand & $\mathrm{Au}(\mathrm{I})$ & $\begin{array}{l}\text { dic prod } \\
\text { Au(III) }\end{array}$ & dimer & $\begin{array}{c}\text { Gold } \\
\text { yield*, } \\
\%\end{array}$ & $\begin{array}{c}\text { Passivation } \\
\text { by oxide }\end{array}$ \\
\hline $\begin{array}{c}\mathrm{Cl}^{-} \\
\mathrm{Br}^{-} \\
\mathrm{SC}\left(\mathrm{NH}_{2}\right)_{2} \\
\mathrm{SCN}^{-}\end{array}$ & $\begin{array}{l}\text { yes } \\
\text { yes } \\
\text { yes }\end{array}$ & $\begin{array}{c}\text { yes } \\
\text { yes } \\
\text { no }\end{array}$ & $\begin{array}{l}\text { no } \\
\text { yes } \\
\text { yes } \\
\text { yes }\end{array}$ & $\begin{array}{l}100 \\
100 * * \\
100^{* *} \\
\text { low }\end{array}$ & $\begin{array}{l}\text { yes } \\
\text { yes } \\
\text { yes } \\
\text { yes }\end{array}$ \\
\hline
\end{tabular}

* For current below the limiting diffusion current of the ligand.

* Decreases at high potentials.

presence of various complexing agents that can be used under these conditions. Comparison of these features with the thermodynamic data of Figure 2 shows that several predicted trends are borne out by observation. For example, $\mathrm{Au}(\mathrm{I})$ is produced as the sole soluble gold species only in the presence of thiourea. The available information for thiocyanate does not permit its inclusion in this comparison but $\mathrm{Au}(\mathrm{I})$ and $\mathrm{Au}(\mathrm{III})$ could be expected to form as products in aqueous thiocyanate solutions. Also, simultaneous oxidation of the ligand is possible at high potentials in all cases, but, as Figure 2 shows, this is most likely to compete with gold dissolution at low potentials in the case of ligands such as thiourea and thiocyanate, whose positions lie close to the diagonal line.

For all practical purposes, only if chloride ions or thiourea are present can metal be dissolved with high current efficiency from a soluble gold anode in acidic solutions. This probably also holds good for the anodic dissolution of gold in electroetching processes. However, in electropolishing, where the metal is dissolved at high current densities under passive conditions, no such limitation applies and the use of any of the ligands could be expected to promote polishing, though with lower current efficiencies.

\section{Acknowledgements}

This article is published by permission of the National Institute for Metallurgy. The enthusiastic and excellent technical assistance of Miss D. A. Velthuis in the preparation of this review is gratefully acknowledged.

\section{References}

I N. V. Sidgwick, "The Chemical Elements and their Compounds', Oxford University Press, 1962

2 N. P. Finkelstein and R. D. Hancock, Gold Bull., 1974, 7, 72

3 G. Milazzo and S. Caroli, "Tables of Standard Electrode Potentials', Wiley, New York, 1978
4 'Encyclopedia of Electrochemistry of the Elements', Vol. IV, edited by A. J. Bard, Marcel Dekker, New York, 1975

5 J. P. Hoare, 'The Electrochemistry of Oxygen', Interscience, New York, 1968

6 R. Woods, in 'Electroanalytical Chemistry', Vol. 9, edited by A. J. Bard, Marcel Dekker, New York, 1976

7 F. G. Will and C. A. Knorr, Ber. Bunsenges., Phys. Chem., $1960,64,270$

8 S. Barnartt, \%. Electrochem. Soc., 1959, 106, 722

9 H. A. Laitinen and M. S. Chao, F. Electrochem. Soc, 1961 , 108,726

10 S. B. Brummer and A. C. Makrides, 9. Electrochem. Soc., 1964 111, 1122

11 G. M. Schmid and R. N. O'Brien, 9. Electrochem. Soc., 1964, 111, 832

12 S. B. Brummer, 7. Electrochem. Soc., 1964, 112, 633

13 A. C. Makrides, f. Electrochem. Soc., 1966, 113, 1158

$14 \mathrm{~K}$. Ogura, S. Haruyama and K. Nagasaki, 9 . Electrochem. Soc., $1971,118,531$

15 G. Grueneberg, Electrochim. Acta, 1965, 10,339

16 J. P. Hoare, Electrochim. Acta, 1966, 11, 203

17 C. M. Ferro, A. J. Callandra and A. J. Arvia, $f$. Electroanal. Chem., 1975, 59, 239

18 D. Dickertmann, J. W. Schultze and K. J. Vetter, F. Elec troanal. Chem., 1974, 55, 429

19 D. A. J. Rand and R. Woods, F. Electroanal. Chem., 1971, 31, 29

20 R. Cordova, M. E. Martins and A. J. Arvia, 9. Electrochem Soc., 1979, 126, 1172

21 S. H. Cadle and S. Bruckenstein, Anal. Chem 1974, 46, 16

22 B. S. Duncan and R. P. Frankenthal, \%. Electrochem. Soc., $1979,126,95$

23 Y. Y. Vinnikov, V. A. Shepelin and V. I. Veselovskii, Electrokhimiya, 1972, 8, 1384

24 D. M. Kolb and J. D. E. McIntyre, Surf. Sci., 1971, 28, 321

25 T. Dickenson, A. F. Povey and P. M. A. Sherwood, \%. Chem. Soc., Faraday Trans. I, 1975, 71, 298

26 E. Schalch and $M$. J. Nicol, Gold Bull., 1978, 11, 117

27 G. Just and R. Landsberg, Electrochim. Acta, 1964, 9, 817

28 T. Heumann and H. S. Panesar, Z. Phys. Chem., 1966, 299, 84

29 J. N. Gaur and G. M. Schmidt, f. Electroanal. Chem., 1970, 24,279

30 J.A. Harrison and J. Thompson, Electroanal. Chem., 1972, 40, 113

31 J. Gallego, C. E. Castellano, A. J. Callandra and A. J. Arvia, 7. Electroanal. Chem., 1975, 66, 207

$32 \mathrm{M}$. J. Nicol and E. Schalch, National Institute for Metallurgy, Johannesburg, Reports Nos. 1844 and 1848

33 J. J. Podesta, R. C. V. Piatti and A. J. Arvia, Electrochim. Acta, $1979, \mathbf{2 4}, 633$

34 S. H. Cadle and S. Bruckenstein, f. Electroanal. Chem., 1973, 48, 325

35 H. Monien, Fresenius Z. Anal. Chem., 1968, 237, 409

36 T. Groenewald, F. S. Afr. Inst. Min. Metall., 1977, 77, 217

37 T. Groenewald, $\mathcal{F}$. Appl. Electrochem., 1975, 5, 71

38 M. F. Martins, C. Castellano, A. J. Callandra and A. J. Arvia, F. Electroanal. Chem., 1977, 81, 291

39 M. M. Nicholson, Anal Chem., 1959, 31, 128

The second part of this article will be published in the July 1980 issue of Gold Bulletin. 